\title{
Clinical Profile of Patients Presenting with Acute Myocardial Infarction in United Arab Emirates: A Tertiary Care Center Government Hospital Experience
}

\author{
Sadeq Tabatabai Nooshin Bazargani Jasem Mohammed Al Hashmi \\ Cardiology Department, Dubai Hospital, Dubai Health Authority, Dubai, UAE
}

\section{Keywords}

Myocardial infarction · Reperfusion therapy · Percutaneous coronary intervention - Acute coronary syndrome .

Cardiology

\begin{abstract}
Background: Acute myocardial infarction (AMI) is one of the major causes of hospitalization and mortality worldwide. There has been limited data available to characterize AMI presentation, contemporary patterns of medical care, and outcomes in Dubai, United Arab Emirates. Methods: A single-center observational registry for patients with AMI was used. All patients admitted to Dubai Hospital with AMI (ST elevation and non-ST elevation) with positive troponin from the mid of August 2017 till the end of April 2018 were included in this registry. Clinical data, prior history, demographics, treatments, and outcomes were recorded from the patient's electronic medical file of the hospital. Result: A total of 329 patients (male $92 \%$, mean age 53.6 years) were included in our registry. The use of ambulance service was only
\end{abstract}

$25 \%$. Electrocardiogram findings of ST-segment elevation myocardial infarction (STEMI) were found in $57 \%$ and nonSTEMI in $43 \%$. History of prior ischemic heart disease was present in $21 \%$ of all cohort, diabetes in $36 \%$, hypertension in $38 \%$, and the current smoking rate was $35 \%$. Reperfusion therapy was provided to $94 \%$ of the patients with STEMI; only $32 \%$ of them had primary angioplasty, and medical reperfusion was performed in $68 \%$. One-third of them received thrombolysis within $30 \mathrm{~min}$, and primary percutaneous coronary intervention $(\mathrm{PCl})$ was provided to $38 \%$ within $90 \mathrm{~min}$. All the patients received aspirin and adenosine diphosphate inhibitors within the first $24 \mathrm{~h}$. The majority of the patients received other key medicines like beta-blocker, statin, and anticoagulant agents within $24 \mathrm{~h}$. The in-hospital mortality rate was about $3 \%$. Conclusions: Using data from the registry may provide an overview of the current status of AMI in Dubai. Medical reperfusion therapy is the most common reperfusion modality in our center, and this will raise the question of whether we need to launch a 24-h primary PCl program in our center.

(c) 2021 The Author(s) Published by S. Karger AG, Basel karger@karger.com www.karger.com/dmj

Karger $\stackrel{\text { ' }}{5}$

BOPEN ACCESS
(C) 2021 The Author(s)

Published by S. Karger AG, Basel

This is an Open Access article licensed under the Creative Common Attribution-NonCommercial-4.0 International License (CC BY-NC) (http://www.karger.com/Services/OpenAccessLicense), applicable to the online version of the article only. Usage and distribution for commercial purposes requires written permission.
Correspondence to:

Sadeq Tabatabai, drsadeq@yahoo.com 


\section{Introduction}

Although acute myocardial infarction (AMI) is one of the leading causes of mortality and one of the major challenges facing the health-care system in the world, there is still a lack of data on the characteristics of patients with AMI in Dubai. In 2010, acute coronary syndrome (ACS) registry from 4 large centers in the United Arab Emirates (UAE-ACS Registry) including patients from Dubai and Rashid Hospital was published. The published data from the UAE-ACS Registry have revealed different characteristics than those from western AMI registries [1].

Carrying the highest mortality rates worldwide, AMI requires special approaches for systematic documentation of occurrence rates and changing trends over time. Using data from the Dubai Hospital AMI registry, we provide an overview of the current status of AMI in Dubai.

The Dubai Hospital AMI registry is a single-center observational registry of patients with AMI admitted to the cardiology unit at Dubai Hospital. This registry presents to the decision-makers and physicians in the real-world clinical field access to the demographic characteristics, risk factors, medications, treatment strategies, and clinical outcomes of patients with AMI. Furthermore, it will provide evidence for the quality of care and the degree of adherence to the international guidelines in the management of AMI derived from the results of clinical trials that have been applied in the clinical practice in our center.

The significant improvement in outcomes is concurrent with the translation and integration of evidencebased AMI care including early myocardial reperfusion, effective antithrombotic therapy, and intensive evidencebased medication into routine clinical practice $[2,3]$.

\section{Method and Material}

Our study is a single-center observational registry of patients with AMI who were admitted to cardiology unit at Dubai Hospital from the mid of August 2017 till the end of April 2018. We included all patients who presented with clinical evidence of AMI characterized by elevation of high sensitive cardiac troponin $\mathrm{T}$ associated with at least one of the following:

1. Symptoms compatible with myocardial ischemia.

2. Development of new abnormal Q waves.

3. ST-T changes are compatible with myocardial ischemia (STsegment elevation or depression, T-wave inversion).

ST-segment elevation myocardial infarction (STEMI) was diagnosed when ST elevation $>1 \mathrm{~mm}$ was seen in at least 2 contiguous leads in any location on the index or qualifying electrocardiogram (ECG), or when presumed new left bundle branch block or documented new $\mathrm{Q}$ waves were observed. In the absence of ST-segment
Table 1. Baseline demographic and clinical characteristics of registry cohort

\begin{tabular}{lc}
\hline Baseline clinical characteristics & $\begin{array}{l}\text { Total } \\
(n=329)\end{array}$ \\
\hline Demographic & \\
Age, mean, years & $53.6 \pm 12$ \\
Male gender & $301(92)$ \\
Weight, mean, kg & $76 \pm 13$ \\
Height, mean, cm & $167 \pm 8$ \\
Past IHD & \\
Prior myocardial infarction & $26(8)$ \\
Prior PCI & $39(12)$ \\
Prior CABG surgery & $5(2)$ \\
Past medical history & \\
Diabetes mellitus & $120(36)$ \\
Current smoker & $115(35)$ \\
Atrial fibrillation & $5(2)$ \\
Hypertension & $126(38)$ \\
Hyperlipidemia & $41(13)$ \\
Dialysis & $3(1)$ \\
Cancer & $3(1)$ \\
Stroke & $6(2)$ \\
Heart failure & $2(1)$ \\
Means of transportation & \\
Ambulance & $82(25)$ \\
Family/Friend & $247(75)$ \\
Type of myocardial infarction & \\
NSTEMI & $142(43)$ \\
STEMI/LBBB & $187(57)$ \\
\hline
\end{tabular}

Data are mean \pm SD or number (\%). PCI, percutaneous coronary intervention; IHD, ischemic heart disease; CABG, coronary artery bypass grafting; STEMI, ST-elevation myocardial infarction; NSTEMI, non-ST-elevation myocardial infarction; LBBB, left bundle branch block.

elevation, patients meeting the inclusion criteria were considered to have non-ST elevation myocardial infarction (NSTEMI). Data were collected from the patient's electronic medical record.

Cardiovascular and noncardiovascular past medical history, risk factors, baseline ECG, patient's demography, baseline clinical course, therapeutic management in the prehospital setting, during the hospital stay, and at discharge were recorded. Left ventricular ejection fraction (LVEF) when assessed at any time during the hospital stay was recorded. Routine laboratory results on admission were collected. In-hospital complications and outcomes specifically information on the occurrence of reinfarction, myocardial revascularization, heart failure, stroke, bleeding events, cardiac arrest, and death were recorded.

\section{Statistical Analysis}

The categorical variables are presented as count and percentages (\%), while the numerical variables are presented as mean \pm standard deviations if it is bell shaped and median [interquartile range] if it is skewed. 
Table 2. Patient's characteristics at presentation

\begin{tabular}{lr}
\hline Characteristics at presentation & $\begin{array}{l}\text { Total } \\
(n=329)\end{array}$ \\
\hline Vital signs at presentation & \\
Systolic blood pressure, mean & $148 \pm 28$ \\
Heart rate, mean & $84 \pm 22$ \\
Clinical presentation & \\
Heart failure & $20(6)$ \\
Cardiogenic shock & $5(2)$ \\
Cardiac arrest & $18(5)$ \\
ECG at presentation & \\
ST elevation & $186(57)$ \\
New or presumed new ST depression & $39(12)$ \\
New or presumed new T-wave inversion & $58(18)$ \\
LBBB & $1(<1)$ \\
Normal & $16(5)$ \\
Transient ST elevation lasting $<20$ min & $9(3)$ \\
Others & $19(6)$ \\
\hline
\end{tabular}

Data are mean $\pm \mathrm{SD}$, or number (\%). ECG, electrocardiogram; LBBB, left bundle branch block.

\section{Results}

\section{Patients' Characteristics}

During the period of the study, our cohort included 329 patients with a final diagnosis of AMI. The demographic details and baseline characteristics are presented in Table 1. The average age was $53.6 \pm 12$ years, and females were the minority and accounted for around $8 \%$ of the cohort. Nationals from the Indian subcontinent (India, Pakistan, and Bangladesh) were found in 232 patients (70\%) of the cohort population. Previous history of ischemic heart disease was found in 70 patients (21\%). History of percutaneous coronary intervention (PCI) was found in $12 \%$ of the patients while $8 \%$ of the patients had a history of previous myocardial infarction.

The most frequent risk factors were hypertension (38\%) and diabetes mellitus (36\%), and the current smoking rate was $35 \%$. A minority of the patient had a history of atrial fibrillation, cancer, and heart failure, and only 3 patients were on regular hemodialysis. Most of the patients arrived at the emergency department (ED) with their own transportation, and ambulances were used in only $25 \%$ of the patients. At presentation, evidence of acute STEMI was found in $57 \%$ while $43 \%$ of the patients presented with acute NSTEMI.

\section{Clinical Findings at Presentation}

On arrival, 20 patients (6\%) had signs of heart failure, 5 patients (2\%) had a cardiogenic shock, and 18 patients
Table 3. Management practice during in-hospital encounter

\begin{tabular}{ll}
\hline Management practice & \\
\hline Door-to-ECG time, min & \\
$\quad$ Mean & $9 \pm 1$ \\
$\quad$ Median & $6[4,8]$ \\
DTN time, min & \\
$\quad$ Mean & $56 \pm 48$ \\
Median & $39[26,67]$ \\
DTB time, min & \\
$\quad$ Mean & $115 \pm 50$ \\
Median & $102[72,149]$ \\
\hline
\end{tabular}

Data are mean \pm SD or median [IQR]. ECG, electrocardiogram; DTN, door-to-needle; DTB, door-to-balloon.

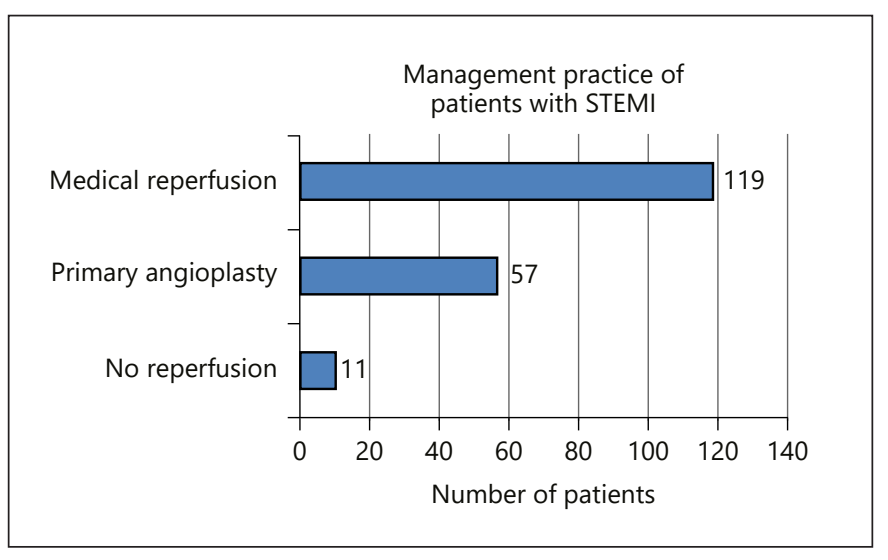

Fig. 1. Reperfusion therapy for the patients who were presented with STEMI. STEMI, ST-segment elevation myocardial infarction.

(5\%) had a cardiac arrest on arrival, four of them had cardiac arrest prehospital (Table 2).

Among patients with acute NSTEMI (142 patients), the ECG changes of $\mathrm{T}$ wave were the most frequent (58 patients) while ST depression was found in 39 patients. Nine patients had transient ST elevation at the time of presentation. Normal ECG was seen in 16 patients (Table 2).

\section{Reperfusion Therapy for STEMI}

In general, the entire cohort had ECG done in the ED. Mean door-to-ECG time was $9 \pm 1 \mathrm{~min}$, and the median was $6[4,8]$ min (Table 3 ).

Among patients who presented with ECG evidence of acute STEMI (187 patients), 176 patients (94\%) received a form of reperfusion therapy and 11 patients $(6 \%)$ did not receive reperfusion therapy (Fig. 1). Symptom onset of $>12 \mathrm{~h}$ from the presentation time (10 patients) was the 
Table 4. In-hospital and discharge pharmacological and intervention treatments

\begin{tabular}{|c|c|}
\hline Pharmacological and interventional treatments & $\begin{array}{l}\text { Total } \\
(n=329)\end{array}$ \\
\hline \multicolumn{2}{|l|}{ Treatment during hospital stay } \\
\hline ACE inhibitor & $186(57)$ \\
\hline $\mathrm{ARB}$ & $26(8)$ \\
\hline Beta-blocker & $293(89)$ \\
\hline Aspirin & $329(100)$ \\
\hline Clopidogrel & $311(95)$ \\
\hline Ticagrelor & $30(9)$ \\
\hline Heparin (unfractionated) & $217(66)$ \\
\hline Heparin (low molecular weight) & $269(82)$ \\
\hline Statin & $309(94)$ \\
\hline Glycoprotein IIB/IIIA inhibitor & $103(31)$ \\
\hline \multicolumn{2}{|l|}{ Treatment at discharge } \\
\hline ACE inhibitor & $200(65)$ \\
\hline $\mathrm{ARB}$ & $28(9)$ \\
\hline Beta-blocker & $292(94)$ \\
\hline Aspirin & $305(98)$ \\
\hline Clopidogrel & $226(73)$ \\
\hline Ticagrelor & $74(24)$ \\
\hline Oral anticoagulation & $7(2)$ \\
\hline Statin & $306(99)$ \\
\hline Other lipid-lowering agents & $7(2)$ \\
\hline \multicolumn{2}{|l|}{ Predischarge intervention } \\
\hline Exercise stress test & 0 \\
\hline Echocardiogram & $297(90)$ \\
\hline$<30 \%$ & $19(6)$ \\
\hline $30-39 \%$ & $65(22)$ \\
\hline $40-50 \%$ & $133(45)$ \\
\hline$>50 \%$ & $80(27)$ \\
\hline Coronary angiogram & $261(79)$ \\
\hline Coronary angioplasty & $202(62)$ \\
\hline $\mathrm{CABG}$ & $4(1)$ \\
\hline
\end{tabular}

Data are number (\%). ACE, angiotensin-converting enzyme; $\mathrm{ARB}$, angiotensin receptor blocker; $\mathrm{CABG}$, coronary artery bypass grafting.

main reason for which patients did not receive reperfusion therapy.

Medical reperfusion therapy with tenecteplase was the most frequent reperfusion strategy used (68\%) (Fig. 1). The mean door-to-needle (DTN) time was $56 \pm 48 \mathrm{~min}$, and the median was $39[26,67] \mathrm{min}$ (Table 3 ). Only $35 \%$ of the patients received thrombolytic therapy within $30 \mathrm{~min}$, and $38 \%$ of the patient underwent primary PCI within $90 \mathrm{~min}$.

Fig. 1 shows that mechanical reperfusion therapy with primary PCI was performed in one-third of the patients presented to the ED with acute STEMI. Actually, 3 patients found to have 3-vessel disease underwent coronary artery bypass grafting (CABG) surgery and 2 patients
Table 5. Main indications for coronary intervention

\begin{tabular}{lc}
\hline Indications for PCI & $\begin{array}{l}\text { Total } \\
(n=202)\end{array}$ \\
\hline PCI for NSTEMI & $73(36)$ \\
PCI for STEMI (stable after successful full-dose lytic) & $55(27)$ \\
PCI for STEMI (stable, >12 h from symptom onset) & $8(4)$ \\
Primary PCI for STEMI & $52(25)$ \\
Rescue PCI (after failed full-dose lytic) & $14(7)$ \\
\hline
\end{tabular}

Data are number (\%). PCI, percutaneous coronary intervention; STEMI, ST-elevation myocardial infarction; NSTEMI, nonST-elevation myocardial infarction.

were found to have spontaneous reperfusion. The average door-to-balloon (DTB) time was $115 \pm 50 \mathrm{~min}$, and the median was 102 [72, 149] min (Table 3).

\section{In-Hospital Management}

Concerning in-hospital medical therapy and intervention, a great proportion of patients received evidencebased medications during their hospitalization and at discharge in our cohort (Table 4). All the patients received aspirin and adenosine diphosphate (ADP) receptor inhibitors (clopidogrel or ticagrelor) within the first $24 \mathrm{~h}$. The majority of the patients received beta-blocker (89\%) and statin therapy (94\%) within the first $24 \mathrm{~h}$. Anticoagulants were administered in 325 patients (99\%) and only 4 patients did not receive anticoagulants. The predominant anticoagulant drug used is low molecular weight heparin, namely, enoxaparin (82\%), while unfractionated heparin was used predominantly during coronary intervention as bolus doses. Only, 10 patients received unfractionated heparin in form of intravenous infusion.

Glycoprotein IIB/IIIA inhibitor was administered in 103 patients (31\%), and the only one used is tirofiban. Out of 142 patients with acute NSTEMI, only 27 patients (19\%) received tirofiban, while out of 187 patients with acute STEMI, 76 patients (41\%) received tirofiban. Table 4 shows that 297 patients (90\%) had their LVEF assessed by echocardiogram before hospital discharge and the majority were having a mild reduction in LVEF (45\%). Coronary angiogram was performed in 261 patients (79\%), and the main reason why coronary angiogram was not done is patient refusal (55 patients, 17\%). Coronary angioplasty was performed in 202 patients (62\%) out of 329 patients, and the reasons for PCI are shown in Table 5. Radial access was used in the majority of the patients who had coronary angioplasty (122 patients, 60\%). 
Four patients underwent CABG before hospital discharge; three of them were admitted with acute STEMI (Table 4).

A record of discharged medication is available for 310 patients (10 patients were discharged against medical advice and 9 patients died; their discharge medications were not recorded). Only 5 patients were discharged without aspirin, and 300 patients (97\%) were discharged on ADP inhibitors, most of them on clopidogrel (74\%). A good portion of the patients were discharged on ACE inhibitors/angiotensin receptor blockers. Statin therapy was used in $99 \%$ of the patients at the time of discharge, and only 11 patients (4\%) were on low-intensity statin therapy (Table 4).

\section{In-Hospital Complications and Mortality}

In-hospital complications were not so common in our registry cohort: heart failure $7 \%$, cardiogenic shock $3 \%$, ventricular tachycardia/fibrillation 5\%, atrial fibrillation $2 \%$, and 21 patients $(6 \%)$ had cardiac arrest. Few patients required intra-aortic balloon pump insertion, and 5 patients $(2 \%)$ required hemodialysis. No stroke was reported. Five patients received blood transfusion; two of them underwent CABG. One patient developed retroperitoneal bleeding. The in-hospital death rate was about 3\% (Table 6).

\section{Discussion}

ACS registries are considered one of the national quality control projects and can be used as a quality indicator for the management of patients with AMI. The previous studies in UAE showed that the average age of the patients with ACS was 51 years and patients with acute STEMI was 47 years $[1,4]$. Our study confirmed these findings that patients with AMI in UAE are probably the youngest patients worldwide. In comparison to the other gulf countries, the average age of the patients with ACS in Qatar was 54 years; Kuwait, 55 years; Saudi Arabia, 61 years; and Oman, 58 years [5-8]. Compare to the developed countries, the average age of the patients with AMI in Europe was found to be about 66 years [9]. Other striking findings are that our patients are predominantly males (92\%) compare to Europe (69\%) and probably that is due to most of the patients in UAE are expatriates (93\%) and most of them are male workers [1,9].

The rate of major risk factors like diabetes mellitus, hypertension, and current smoking was different from those found in other regional and international registries. Onethird of our patients were diabetic compare to $48 \%$ in $\mathrm{Ku}$ -
Table 6. In-hospital complications and outcome

\begin{tabular}{lc}
\hline Complications and outcomes & $\begin{array}{l}\text { Total } \\
(n=329)\end{array}$ \\
\hline Heart failure & $23(7)$ \\
Cardiogenic shock & $9(3)$ \\
Intra-aortic balloon pump & $3(1)$ \\
Dialysis & $5(2)$ \\
Bleeding & $1(<1)$ \\
Blood transfusion & $5(2)$ \\
Stroke & 0 \\
Atrial fibrillation & $5(2)$ \\
Ventricular tachycardia/Fibrillation & $16(5)$ \\
Cardiac arrest & $21(6)$ \\
Reinfarction & $3(1)$ \\
Death & $9(3)$ \\
\hline
\end{tabular}

Data are number (\%).

wait, $41 \%$ in Qatar, and one-fourth in Europe $[5,6,9]$. The UAE-ACS Registry showed that the rate of diabetes mellitus was $39 \%$, and it was $28 \%$ in patients with acute STEMI in UAE $[1,4]$. The rate of hypertension was relatively low in our cohort (38\%), while the rate of hypertension in Kuwait and Qatar was 49 and 41\%, respectively $[5,6]$. While in Europe, the rate of hypertension was $58 \%$ in patients with ST elevation and $65 \%$ in patients with non-ST elevation ACS [9]. The smoking rate among patients with ACS in Kuwait was $40 \%$, and $33 \%$ of the patients with ACS were smokers in Qatar [5, 6]. While in Europe, the rate of smoking was $37 \%$ in patients with ST elevation and $24.5 \%$ in patients with non-ST elevation ACS [9]. Despite our patients being relatively young, about one-fifth of them reported a previous history of ischemic heart disease.

More than half of our patients were presented with ECG changes suggestive of STEMI compare to about $60 \%$ in Europe [9]. Only $82(25 \%)$ patients arrived at the hospital by ambulance compare to $17.3 \%$ in the previous registry [1]. Although this survey shows evidence of improvement in utilizing ambulance service in the UAE, we believe that we should intensify the public awareness about symptoms and signs of ACS in the society, and the use of ambulance services in case of chest pain should be encouraged.

The use of key medicine like aspirin, ADP inhibitors, beta-blockers, ACE inhibitors/angiotensin receptor blockers, and statin was comparable to what was reported in Europe [9]. The different socioeconomic classes between expatriates ( $70 \%$ from the Indian subcontinent) and the UAE nationals did not prevent them from receiving reperfusion therapy and other key medications unlike 
what has been shown in India for example [10]. However, follow-up treatment could be different as patients do not receive this free of charge.

This registry showed that the medical reperfusion therapy with tenecteplase is the main reperfusion strategy in our center, and only $32 \%$ of the patients with STEMI underwent primary PCI. Yet, DTN and DTB time is not optimal as recommended by international guidelines like American Heart Association and European Society of Cardiology $[11,12]$. On the other hand, this survey showed that the majority of the patients with STEMI had a form of reperfusion therapy, and despite improvements in the rate of primary PCI compared to the previous UAE-ACS Registry (17\%), the rate of primary PCI is still very low among our patients [1]. This will raise the question of whether we need to launch a 24-h primary PCI program in our center. Measures need to be taken to improve DTB and DTN time in our center.

Overall in-hospital morbidity and mortality rate are relatively low. The rate of death among patients with ACS in Kuwait was 2.7\%, while in Saudi Arabia, Oman, and Europe were $4.5,4.3$, and $6.3 \%$ respectively [6-9]. The inhospital mortality rate of patients with ACS in India was found to be $6.7 \%$ [10]. Our patients were quite young, a feature likely to contribute to the low mortality rate.

\section{Limitations}

This study is a single-center experience on the management of AMI patients in form of STEMI and NSTEMI in Dubai, United Arab Emirates. The number of patients is relatively small, and the follow-up mortality and morbidity data post patients' discharge are not available.

\section{Conclusion}

Overall, this registry may provide an overview of the current status of AMI presentation, management, and clinical outcomes in Dubai. The majority of our patients attended for medical attention on their own rather than by ambulance. This shows the need to improve public awareness regarding using ambulance service in case of chest pain. The in-hospital morbidity and mortality are low, but unfortunately, we do not know their 30 days and longer mortality and morbidity data. This study showed that the primary PCI is not the main reperfusion therapy in our center, and measures need to be taken for improvements.

\section{Statement of Ethics}

All procedures performed in studies involving human participants were in accordance with the ethical standards of the Dubai Health Authority (DHA) Ethics Committee. The approval details are as follows: 1) Medical Research Committee: MRC 06/2013_15 dated Feb 24, 2014; 2) Dubai Scientific Research Ethics Committee (DSREC), extended approval: DSREC 07/2017_06 dated Aug 1, 2017.

\section{Conflict of Interest Statement}

The authors declared no potential conflicts of interest with respect to the research, authorship, and/or publication of this article.

\section{Funding Sources}

The authors received no financial support for the research, authorship, and/or publication of this article.

\section{Author Contributions}

All the authors contributed equally in writing the manuscript. All authors read and approved the final manuscript.

\section{References}

1 Yusufali AM, AlMahmeed W, Tabatabai S, Rao K, Binbrek A. Acute coronary syndrome registry from four large centres in United Arab Emirates (UAE-ACS Registry). Heart Asia. 2010;2(1):118-21.

2 Gibson CM, Pride YB, Frederick PD, Pollack CV, Canto JG, Tiefenbrunn AJ, et al. Trends in reperfusion strategies, door-to-needle and door-to-balloon times, and in-hospital mortality among patients with ST-segment eleva- tion myocardial infarction enrolled in the $\mathrm{Na}$ tional Registry of Myocardial Infarction from 1990 to 2006. Am Heart J. 2008;156(6):103544.

3 Barakat K, Wilkinson P, Suliman A, Ranjadayalan K, Timmis A. Changing face of acute myocardial infarction in east London: a prospective cohort study of trends in management and outcome in the reperfusion era. J Cardiovasc Risk. 2001;8:21-9.
4 Binbrek AS, Rao NS, Van de Werf F, Sobel BE. Meta-analysis of studies of patients in The United Arab Emirates with ST-elevation myocardial infarction treated with thrombolytic agents. Am J Cardiol. 2010;106(12):1692-5.

5 El-Menyar A, Ahmed E, Albinali H, Al-Thani $\mathrm{H}$, Gehani A, Singh R, et al. Mortality trends in women and men presenting with acute coronary syndrome: Insights from a 20-year registry. PloS One. 2013;8(7):e70066. 
6 Zubaid M, Rashed WA, Saad H, Attiya A, AlBanat BA, Ridha M, et al. Kuwait acute coronary syndromes registry: baseline characteristics, management practices and in-hospital outcomes of patients hospitalized with acute coronary syndromes in Kuwait. Med Princ Pract. 2007;16(6):407-12.

7 Assiri AS. Gender differences in clinical presentation and management of patients with acute coronary syndrome in southwest of saudi arabia. J Saudi Heart Assoc. 2011;23(3):135-41.
8 Panduranga $\mathrm{P}$, Sulaiman K, Al-Zakwani I. Acute coronary syndrome in oman: results from the gulf registry of acute coronary events. Sultan Qaboos Univ Med J. 2011; 11(3):338-42.

9 Puymirat E, Battler A, Birkhead J, Bueno H, Clemmensen P, Cottin Y, et al. Euro heart survey 2009 snapshot: regional variations in presentation and management of patients with AMI in 47 countries. Eur Heart J Acute Cardiovasc Care. 2013;2(4):359-70.

10 Xavier D, Pais P, Devereaux PJ, Xie C, Prabhakaran D, Reddy KS, et al. Treatment and outcomes of acute coronary syndromes in India (CREATE): a prospective analysis of registry data. Lancet. 2008;371(9622):1435-42.
11 ESC Scientific Document Group. Borja I James S, Agewall S, Antunes MJ, BucciarelliDucci C, Bueno H, et al. 2017 ESC Guidelines for the management of acute myocardial infarction in patients presenting with ST-segment elevation: the Task Force for the management of acute myocardial infarction in patients presenting with ST-segment elevation of the European Society of Cardiology (ESC). Eur Heart J. 7 Jan 2018;39(2):119-77.

12 ACC/AHA guidelines for the management of patients with ST-elevation myocardial infarction. Circulation. 2018;110(9):e82-e292. 